\title{
Adaptation of Proteasomes and Lysosomes to Cellular Environments
}

\author{
Yohannes Afework Mebratu, Zerihun Hailemariam Negasi $\mathbb{D}$, Saugata Dutta, \\ Joselyn Rojas-Quintero and Yohannes Tesfaigzi *
}

Pulmonary and Critical Care Medicine Division, Department of Medicine, Brigham and Women's Hospital, Harvard Medical School, Boston, MA 01255, USA; ymebratu@bwh.harvard.edu (Y.A.M.);

znegasi@bwh.harvard.edu (Z.H.N.); sdutta@bwh.harvard.edu (S.D.); jrojasquintero@bwh.harvard.edu (J.R.-Q.)

* Correspondence: YTesfaigzi@bwh.harvard.edu

Received: 28 August 2020; Accepted: 26 September 2020; Published: 1 October 2020

check for updates

\begin{abstract}
Protein degradation is important for proper cellular physiology as it removes malfunctioning proteins or can provide a source for energy. Proteasomes and lysosomes, through the regulatory particles or adaptor proteins, respectively, recognize proteins destined for degradation. These systems have developed mechanisms to allow adaptation to the everchanging environment of the cell. While the complex recognition of proteins to be degraded is somewhat understood, the mechanisms that help switch the proteasomal regulatory particles or lysosomal adaptor proteins to adjust to the changing landscape of degrons, during infections or inflammation, still need extensive exploration. Therefore, this review is focused on describing the protein degradation systems and the possible sensors that may trigger the rapid adaptation of the protein degradation machinery.
\end{abstract}

Keywords: protein degradation; core particle; regulatory particle; endosome; autophagy; aggresome

\section{Background}

Protein homeostasis or "proteostasis", the balance of the synthesis and degradation of proteins, is closely associated with cellular compartments, including the Golgi apparatus, the endoplasmic reticulum (ER), and the lysosome [1]. The ER is not only responsible for the synthesis of the protein backbone, but also for monitoring the quality of the newly synthesized proteins through the unfolded protein response (UPR) system and shuttles misfolded proteins into the degradation pathway. The ubiquitin-proteasome and the autophagy-lysosome systems ensure selective degradation of proteins. Depending on the cell type, the relative contribution of the proteasome and autophagy systems may vary considerably, but the current accepted estimate is that the proteasome is responsible for the great majority (up to $80 \%$ ) of the protein degradation in the majority of growing mammalian cells. However, in muscle cells, for example, autophagy can account for $40 \%$ of degradation of long-lived proteins [2]. The crosstalk between these two proteolytic pathways increases the capacity to process protein degradation and participates in the recycling of the compounds [3]. Should the degradation of proteins be overwhelmed despite both degradation pathways being activated, unwanted proteins are sequestered into aggresomes to prevent toxicity to the cell.

This review will focus on the mechanisms that provide the plasticity of these degradation systems to adapt to physiological changes, including viral and bacterial infections or exposure to environmental insults that increase reactive oxygen species (ROS).

\section{Proteasome Plasticity}

The term "proteasome" covers multiple types of entities that share a common proteolytic core, the catalytic $20 \mathrm{~S}$ core particle (also called $20 \mathrm{~S} \mathrm{CP}$ ). The $20 \mathrm{~S}$ proteasome barrel is capped by different 
regulatory particles (RPs) or proteasome activators (PA) [4], including the19S, PA28 $\alpha / \beta, \mathrm{PA} 28 \gamma$, or PA200 that can be on one or both sides of the barrel (Figure 1) [5]. At baseline, up to $75 \%$ of $20 \mathrm{~S} \mathrm{CP}$ remain uncapped, and the caps maintain the $20 \mathrm{~S}$ core open and are crucial for binding and processing of the substrates [6]. Therefore, proteasomes should be viewed as being composed of building blocks that serve in the degradation of specific set(s) of substrates. This arrangement likely is crucial to cope with the diversity of the substrate types, the cellular compartments, and the speed by which proteins need to be processed.

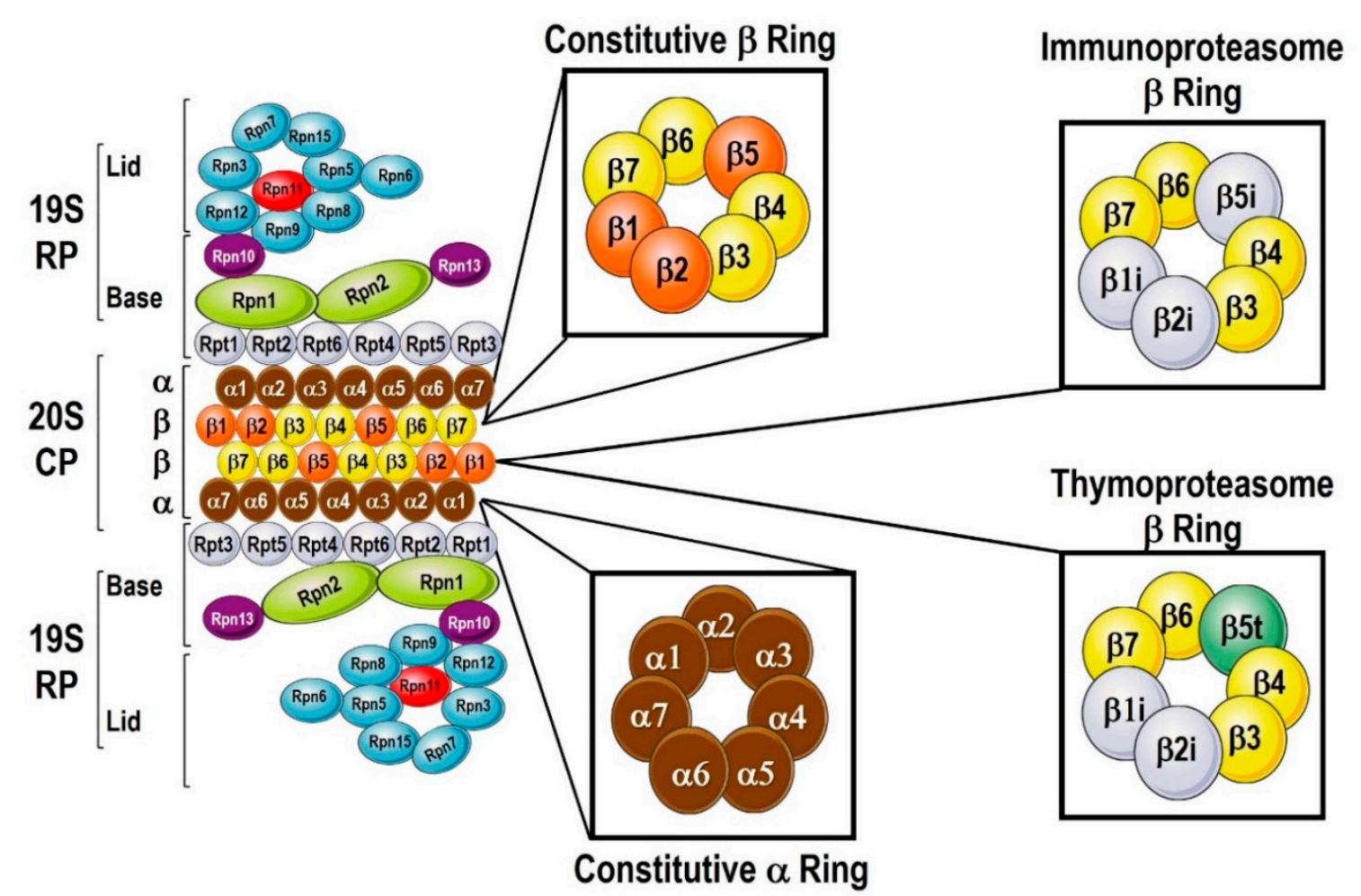

Figure 1. Proteasomal components. The proteasome can be divided into the 2 main structures: the $20 \mathrm{~S}$ core protease (CP) and the 195 regulatory particle (RP). The $20 \mathrm{~S}$ consists of $\alpha$ and $\beta$ subunits, with 7 $\alpha$-subunits forming the $\alpha$-ring, and $7 \beta$-subunits forming the $\beta$-ring. When the immunoproteasome is activated, there are $3 \beta$-subunits that are replaced, $\beta 1 \mathrm{i}$ for $\beta 1, \beta 2 \mathrm{i}$ for $\beta 2$, and $\beta$ i for $\beta$ to form the Immunoproteasome. The CP in the thymus is equipped by $\beta 5$ t instead of the $\beta 5$. The 19S RPs is a protein-complex made out 6 subunits of Rpt and 13 subunits of Rpn proteins important to keep the 20S $\mathrm{CP}$ open and to bind and process ubiquitylated proteins for degradation.

The $20 \mathrm{~S}$ Core Particle is a $700 \mathrm{kDa}$ protein complex [5], with a cylinder-like assembly that is made up of four axially stacked heptameric rings $[5,6]$. The two rings in the middle part consist of $\beta$ subunits and are sandwiched between two $\alpha$ rings, ultimately forming a $\alpha_{1-7}, \beta_{1-7}, \beta_{1-7}, \alpha_{1-7}$ pattern (Figure 1). Seven similar but different subunits, $\alpha_{1}$ through $\alpha_{7}$, form the $\alpha$ ring and the $N$-termini of a subset of $\alpha$ subunits form the pore that controls the entry of incoming substrates. Several $\alpha$ subunits possess a nuclear localization signal and contribute to the subcellular localization of the proteasomes [7]. The $\beta$ rings are made up of $\beta_{1-7}$ subunits, but only the $\beta_{1}, \beta_{2}$ and $\beta_{5}$ subunits show peptidylglutamyl-peptide-hydrolyzing, trypsin-like, and chymotrypsin-like catalytic activity, respectively $[5,6]$. Interestingly, individual overexpression of the catalytic subunits $\beta 5$ and $\beta 1$ is enough to increase the number of proteasomes in the cell. 
19S Regulatory Particle consists of the Regulatory Particle of Triple-A ATPase (Rpt) subunits (Rpt1-Rpt6) and Regulatory Particle of Non-ATPase (Rpn) subunits (Rpn1-Rpn15) ranging 10-100 kDa in size, forming two sub-complexes, the lid and the base (Figure 1) [5]. The 19S particle Rpn1, Rpn10 and Rpn13 of the lid sub-complex act either directly [8]. via their own ubiquitin-binding domains (UBDs) or indirectly via the UBDs of shuttling proteins, such as p62 or Rad23 [9]. Deubiquitylation of incoming substrates is carried out by the deubiquitylating enzymes (DUBs) Rpn11, Uch37, and Ubp6/Usp14 [10]. The C-terminal domain of Rpn13 may also have deubiquitylating attributes, but the functions of the remaining lid subunits are largely unknown [6]. The Rpt subunits have a key role to provide energy for proteolysis, in an ATP-dependent process, to unfold the substrates and inject them into the 20S core. Further, Rpt2, Rpt3 and Rpt5 proteins possess conserved C-terminal motifs that allow insertion into the pockets between two contiguous $\alpha$ subunits of the 20S core particle [11]. Such insertion of Rpt subunits promotes $\alpha$ subunit rotation which facilitates gate opening and maintaining the open-gate conformation [5].

The lid and the base sub-complexes are formed independently before they are connected by the Rpn10 subunit [7]. Rpn14 (in mammals PAAF1 - proteasomal ATPase-associated factor 1) along with p28/gankyrin [12], 26S Proteasome Non-ATPase Regulatory Subunit 9 (also known as p27,PSMD9, bridge-1,RPN4), and S5b [13] serve as chaperones to facilitate the assembly of the 19S particle [14]. Such chaperones may also be important in the adaptation process of proteasomes.

The Protein activator (PA28) Regulatory or 11S Particle exists in two major forms, PA28 $\alpha / \beta$ and PA28 $\gamma$. While the constitutive proteasome is composed of the 20S CP and a single or double 19S cap to form the $26 \mathrm{~S}$ and $30 \mathrm{~S}$ proteasomes, respectively, when cells are exposed to inflammatory stimuli, such as TNF- $\alpha$ or IFN- $\gamma$, immunoproteasomes are assembled (Figure 2). When cells are exposed to IFN- $\gamma$, three genes, $\beta 1 \mathrm{i}, \beta 2 \mathrm{i}$, and $\beta 5 \mathrm{i}$, (the $i$ for inducible), replace the constitutive active subunits $(\beta 1, \beta 2$, and $\beta 5$, respectively). In addition, INF- $\gamma$ exposure also induces proteasome maturation protein (POMP) expression which facilitates assimilation of $\beta 1 \mathrm{i}, \beta 2 \mathrm{i}$ and $\beta 5 \mathrm{i}$ into the $20 \mathrm{~S}$ core particle. The 195 particle dissociates from the 20S CP $[15,16]$ along with recruitment of PA28 $\alpha / \beta$ RP in the cytosol or PA28 $\gamma$ in the nucleus, to form the "immunoproteasome" [15]. When PA200 is recruited, there is increased hydrolysis of peptide-sized substrates instead of larger intact proteins. Hybrid proteasomes can have a $19 S$ and any of the activated regulatory particles, PA28 $\alpha$, PA28 $\beta$, and PA200. In addition, iProteasome may be comprised of 11S, 20S, and 11S, or 19S cap, 20S, and 11S components (Figure 2). Hybrid immunoproteasomes, doubled-capped as PA28 $\alpha / \beta-20 S-19 S$, can form that are able to hydrolyze tri- and tetra-peptides more efficiently than the $26 \mathrm{~S}$ proteasome [17]. The speedy assembly of immunoproteasomes [18], is crucial to process major histocompatibility complex (MHC) class I molecules during the early stages after infection [19]. However, the mechanisms that regulate the transition from one cap to another for the 20S CP are largely unknown. It is possible that different forms of the $20 \mathrm{~S}$ proteasome coexist in the same cell, and even that a single $20 \mathrm{~S}$ proteasome can be built of distinct $\alpha$ - or $\beta$-rings (Figure 2). In addition, different types of regulatory particles can be attached to the 20S CP either on one or both sides of the barrel (Figure 2).

A proteasome that is exclusively expressed in the thymus, designated as "thymoproteasome", is found only in both human and mouse cortical thymic epithelial cells (cTECs) and has similar catalytic subunits as immunoproteasomes, except $\beta 5 \mathrm{t}$ instead of $\beta 5 \mathrm{i}$. The $\beta 5 \mathrm{t}$ subunit is most closely related to $\beta 5$ and $\beta 5 \mathrm{i}$ subunits while the other two catalytic subunits in the thymoproteasome are $\beta 1 \mathrm{i}$ and $\beta 2 i$, not $\beta 1$ and $\beta 2$. Thymoproteasome make up the majority of the proteasomes in cTECs, while the standard and immunoproteasomes are minimally represented [20]. 


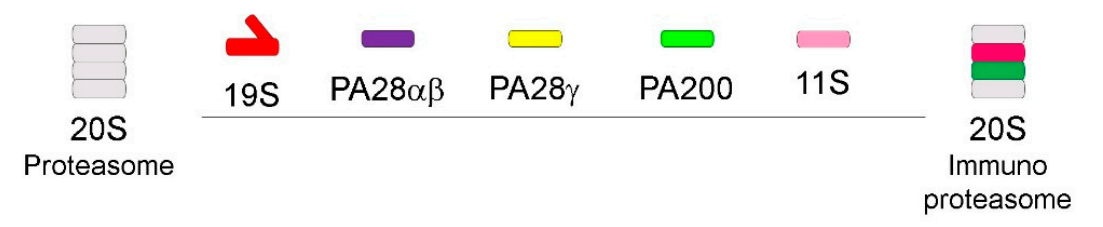

\section{Constitutive}

Inducible

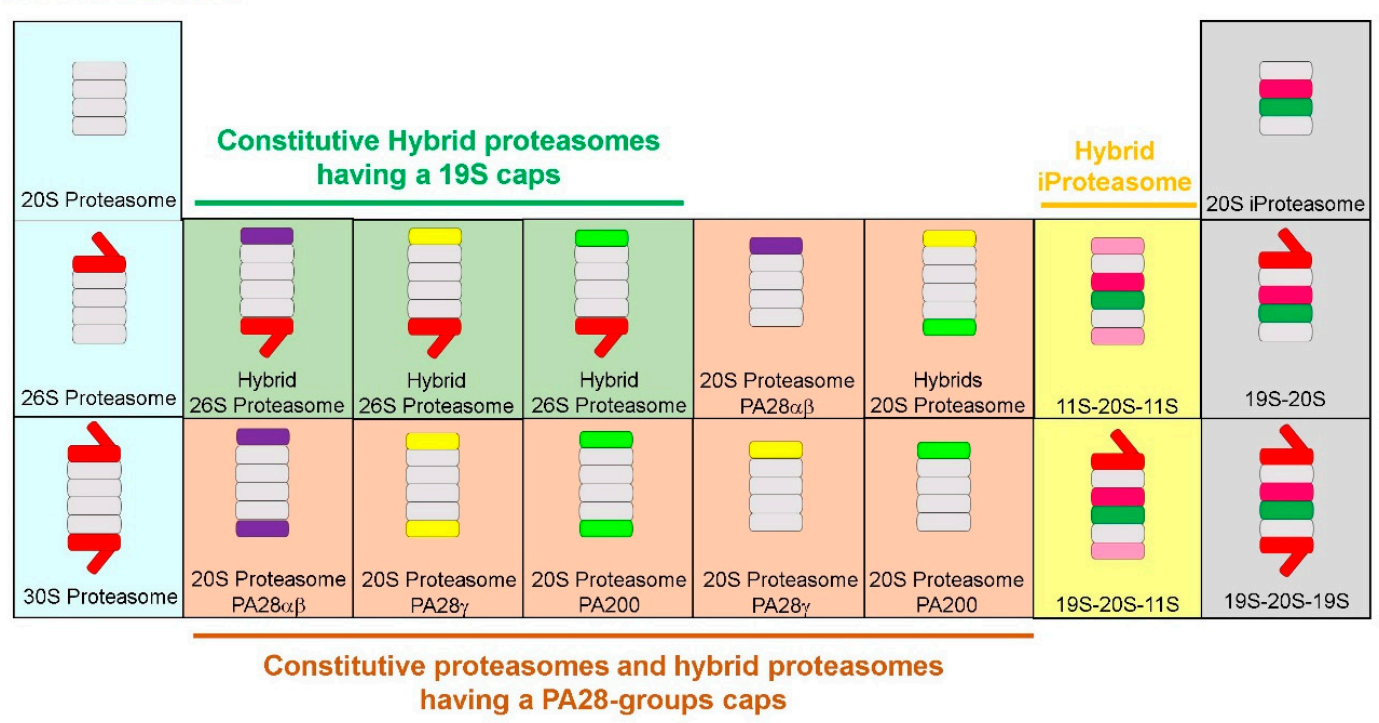

Figure 2. Types of Proteasomes. The constitutive proteasome is composed of the 20S CP and a single or double 195 cap to form the $26 \mathrm{~S}$ or $30 \mathrm{~S}$ proteasomes, respectively. When cells are exposed to inflammatory stimuli, i.e., TNF- $\alpha$ or IFN- $\gamma$, immunoproteasomes are assembled. The 20S CP incorporates $\beta$ i-Ring, and is capped by PA28 $\alpha / \beta$, PA28 $\gamma$, and PA200 caps on either one of both sides. Hybrid proteasomes have a 19S cap mixed with any of the activated caps (PA28 $\alpha / \beta$, PA28 $\gamma$, and PA200). Hybrid iProteasome may be comprised of 11S, 20S, and 11S, or 19S cap, 20S, and 11S components. The inducible proteasome is composed of the 20S iProteasome and a single or double 19S cap to form the 19S-20S or 19S-20S-19S proteasomes, respectively.

Proteasomal components are heavily enriched in membrane-less organelles, also called proteasome storage granules (PSGs) [21]. As soon as the cell receives a signal of proliferation, such as glucose addition, PSGs disappear and proteasomes are repositioned into the nucleus. Therefore, proteasomes are located in perinuclear region during the G1 and early $S$ phases and move to the periphery during G2 phase aided by cytoskeletal elements [22]. Up to 90\% nuclear proteasomes can migrate to the cytoplasm the longer cells are in the quiescent state. RPN1 anchors proteasomes to the ER to form the endoplasmic reticulum-associated degradation (ERAD), less than $20 \mathrm{~nm}$ from the nucleus, whereas RPN9 anchors proteasomes to the nuclear pore complex (NPC) sites. Nuclear tethering of the proteasomes, for inner nuclear membrane-associated degradation (INMAD) [23,24], is mediated on two sites through RPN9 [21], on the or the nuclear core complex (NPC) via nuclear basket myosin-like protein (Mlp) - NPC interactome and directly via direct interaction with the Esc1p (Establishes silent chromatin 1p) [25].

\section{Recognition of Proteins by the Proteasome}

Proteins designated for degradation are tagged by ubiquitin, a protein composed of 76 amino acids. This tag is linked to the lysine residues of targeted proteins by 3 enzymes in an ATP-dependent process. Briefly, the E1 enzymes activate ubiquitin in an ATP-dependent manner and form E1-ubiquitin thioester. Then, the activated ubiquitin is transferred to E2 enzymes through an E2-ubiquitin thioester, Finally, an E3 ligase facilitates the formation of the isopeptide bond between the Lys of the substrate and 
the C-terminal tail of ubiquitin [26]. In the human proteome, there are only two E1, with 40 E2 ligases; however there are over $600 \mathrm{E} 3$ ligases facilitating protein ubiquitylation (Table 1), suggesting that the specificity which protein undergoes ubiquitylation is determined by the E3 ligases [27]. The removal of the ubiquitin residue is regulated by six families of deubiquitinases (DUBs) (Table 1). Ubiquitin is recognized by 20 families of ubiquitin binding domains (UBDs), some of which are in RPN1, Rpn10 and Rpn13 [28]. The ubiquitin binding domains (UBDs) may differ in their affinity and avidity for distinct ubiquitin linkages, but their common feature is the single or multiple $\alpha$-helices, zinc finger motifs, or pleckstrin-homology domains. Other UBD types show structural similarity to E2 conjugating enzymes without the catalytic activity UBDs can have ubiquitin-binding specificity, recognizing between the different ubiquitin tags. For example, BRAP (RNF52) preferentially binds to M1- and K63-linked di-ubiquitin chains, weakly to K27-linked chains, but not to K6-, K11-, or K48-linked chains [29]. The presence of several UBDs within the same protein not only increases the affinity to polyubiquitin chains, but can also change the avidity and determines linkage selectivity [30].

Table 1. Ubiquitinases and Deubiquitinases.

\begin{tabular}{|c|c|c|c|}
\hline Ubiquitin Ligases & $\begin{array}{l}\text { Number of } \\
\text { Ligases }\end{array}$ & Deubiquitinases & $\begin{array}{l}\text { Number of } \\
\text { DUBs }\end{array}$ \\
\hline $\begin{array}{l}\text { Tag Proteins with } \\
\text { Ubiquitin Residues }\end{array}$ & & $\begin{array}{l}\text { Remove a Ubiquitin Residue from } \\
\text { Proteins. }\end{array}$ & \\
\hline $\begin{array}{l}\text { Ubiquitin activating } \\
\text { enzyme E1 Ligase }\end{array}$ & 2 & $\begin{array}{l}\text { Cystein Proteases: } \\
\text { i. Ubiquitin specific proteases (USPs) } \\
\text { ii. Ubiquitin carboxy-terminal hydrolases } \\
\text { (UCHs) } \\
\text { iii. Ovarian-tumor proteases (OTUs) } \\
\text { iv. Machado-Joseph disease protein } \\
\text { domain proteases (MJDs) } \\
\text { v. Monocyte chemotactic protein-induced } \\
\text { proteins (MCPIPs) } \\
\text { vi. Permuted papain fold peptidases of } \\
\text { dsRNA viruses and eukaryotes (PPPDEs) }\end{array}$ & $\begin{array}{c}62 \text { USPs } \\
4 \text { UCHs } \\
15 \text { OTUs } \\
4 \text { MJDs } \\
7 \text { MCPIPs }\end{array}$ \\
\hline $\begin{array}{l}\text { Ubiquitin conjugating } \\
\text { enzyme E2 Ligase }\end{array}$ & 40 & \multirow{2}{*}{$\begin{array}{l}\text { Zinc-dependent metalloproteinases: } \\
\text { i. JAMMs/MPN+ proteases }\end{array}$} & \multirow[b]{2}{*}{4 JAMMs } \\
\hline $\begin{array}{l}\text { Ubiquitin ligating } \\
\text { enzymeE3 Ligase }\end{array}$ & 600 & & \\
\hline
\end{tabular}

The proteasome can also bind polyubiquitylated substrates through proteins with ubiquitin like (UBL) domains that transiently associate with the 19S [31]. The best-studied UBL motifs are those interacting with SUMO, known as SUMO-interacting motifs (SIMs) and autophagy-related protein ATG8/LC3.

However, proteins containing unstructured regions, including p53, p73 $\alpha, \mathrm{p} 21^{\mathrm{Cip} 1} \mathrm{I} \kappa \mathrm{B} \alpha$, MCL-1 and BIM, can be degraded in an Ub-independent manner by $20 \mathrm{~S}$ proteasomes in vitro [32,33]. Also, ubiquitin-independent proteasomal degradations have been described for a wide range of proteins that possess unstructured peptide domains located within proteins for recognition by the proteasome [34,35]. For example, IKB $\alpha$ is constitutively degraded by the proteasome through a ubiquitin-independent mechanism [36]. Additionally, treatment of cells with dicoumarol, an inhibitor of NAD(P)H quinone oxidoreductase 1, induces p53 degradation by a proteasome-dependent, ubiquitin-independent mechanism [32].

\section{Lysosomal Degradation and Recognition of Ubiquitylated Proteins}

Lysosomes arise from the fusion of late endosomes that contain material taken up at the cell surface with transport vesicles that bud from the trans-Golgi network [37]. The lysosome can exhibit multiple tridimensional conformations, is highly dynamic, and is considered as a signaling hub because of its many possible functions [38]. The complex function stems partly from the 7-10 nm 
thick membrane that harbors 120 membrane-bound proteins not only maintaining intraluminal $\mathrm{Na}^{+}$, $\mathrm{K}^{+}, \mathrm{Cl}^{-}, \mathrm{Ca}^{2+}$ ion concentrations and $\mathrm{pH}(\mathrm{pH} 5)$ [39], but also selectively mobilizing and accepting cargo by for example, the Lysosome Associated Membrane Proteins (LAMP)-1-3 and Lysosomal Integral Membrane Protein (LIMP-2). Encapsulated within the lysosome are $\sim 60$ acid hydrolases (e.g., glycosidases, proteases, lipases, nucleases, phosphatases, and sulfatases) that are responsible for the degradation of nucleic acids, proteins, lipids and carbohydrates [40]. Lysosomes are generally localized in the peri-nuclear region that is facilitated by E3 ligase RiNg Finger protein-26 (RNF26) controlling the microtubule-dependent transport of early and late endosomes [41]. In neuronal cells, transport of lysosomes is controlled by dynein motor proteins, that are associated with intermediate, light-intermediate, and dynein light chains [42]. The number of endolysosomal organelles as well as their fission and fusion in the perinuclear area is controlled by the ER through a complex system of tethering proteins [43].

Just as the proteasomal system is crucial for the normal turnover of cellular proteins, basal autophagy is crucial for intracellular quality control to selectively dispose of aberrant protein aggregates and damaged organelles. Aggresomes are confined by vimentin fibers and are enriched in the microtubule-organizing center (MTOC), attract chaperones and proteasomes, and serve as protein quality-control centers. Terminally aggregated proteins accumulate in an insoluble protein deposit (IPOD) and these IPODs exhibit a low rate of molecular exchange with the cytosol and are highly immobile [44]. These aggregates can induce autophagosome formation as they are large enough to allow simultaneous binding of multiple receptors to its surface.

In addition, some cell surface and integral membrane proteins [45], internalized ligands, larger protein aggregates including proteasomes, cellular organelles such as mitochondria, intracellular parasites, such as bacteria are degraded by the autophagy-lysosome pathway (Table 2) [46].

Table 2. Selective autophagy receptors.

\begin{tabular}{ccc}
\hline Adapter Protein & Interaction Domain & Selective Autophagy Involved in \\
\hline p62/SQSTM1 & UBA & Aggrephagy, mitophagy, xenophagy, pexophagy and zymophagy \\
NBR1 & UBA & Aggrephagy, mitophagy, xenophagy \\
Optineurin & UBAN, UBZ & Aggrephagy, mitophagy, xenophagy \\
NDP52 & UBZ & Aggrephagy, mitophagy, xenophagy \\
BNIP3L/NIX & - & Mitophagy \\
FUNDC1 & - & Mitophagy \\
HDAC6 & - & Aggrephagy and mitophagy \\
\hline
\end{tabular}

\section{Ubiquitin-Like Proteins and Adaptors for Selective Autophagy}

Autophagy requires the ubiquitin-like (UBL) protein, Atg12, to be conjugated to a conserved Lys residue of Atg5 and Atg16 [47] and together with an E2-like enzyme, Atg3, catalyzes the transfer of the activated microtubule-associated protein 1 light chain 3 beta (MAP1LC3B [48]. The lipidated LC3 (often referred to as LC3-II) allows for substrate uptake upon binding to several autophagy receptors [49]. This complex regulates closure of the phagophore by interacting with Cdc48/p97. [50], and by recruiting selective adaptors described below, directs specific targets to the lysosome for degradation [51,52].

The sequestosome 1 (p62/SQSTM1), the first described mammalian autophagy receptor, is involved in regulating reactive oxygen species (ROS), apoptosis, inflammation, and autophagy [53-55]. It consists of an N-terminal Phex and Bem1p (PB1) domain [56], a zinc finger (ZnF) domain, Light Chain 3 (LC3) interacting region (LIR) [53,57], TRAF6-binding (TB), and ubiquitin-associated (UBA) domains [55] (Figure 3). The Keap-interacting region (KIR) interacts with Keap1 and affects the transcription factor Nrf2 and thereby controls ROS level [58]. The PB1 motif allows p62 to interact with itself and other PB1 domain-containing proteins and thereby hetero-, homo-, or polymerize. It is assumed that p62 first self-oligomerizes via its PB1 domain and thereby initiates aggregate formation of polyubiquitylated proteins, because individual p62 units poorly interact with ubiquitin [59]. In certain conditions, aggregates containing p62 and ubiquitylated proteins may even serve as a nucleating 
scaffold for autophagosome biogenesis, potentially by associating with mTORC1 and multiple Atg8/LC3 proteins $[59,60]$. The growing double membrane starts to enclose the p62-containing aggregates due to interactions between p62, Atg8/LC3, and other Atg proteins [61].

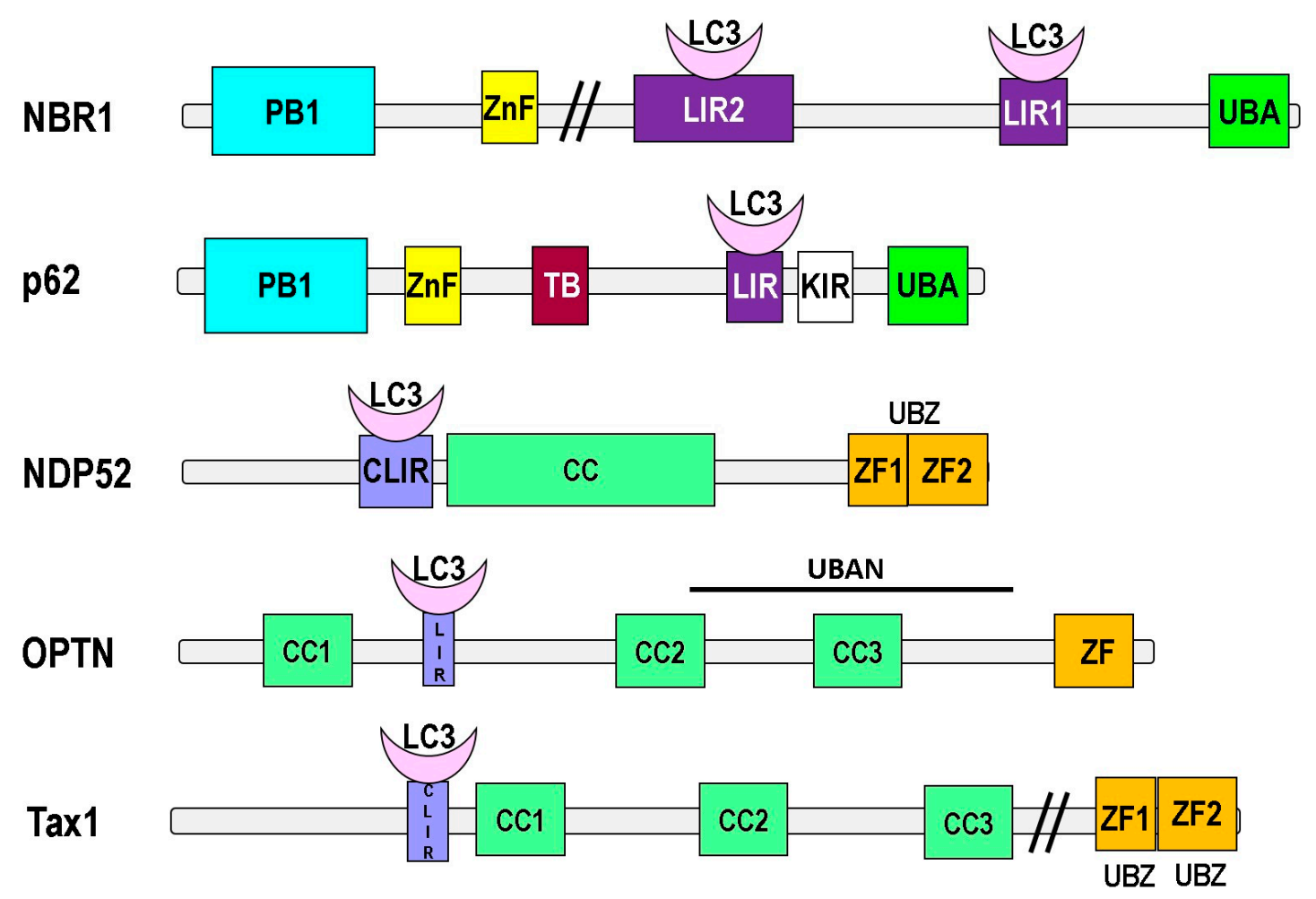

Figure 3. Autophagy adaptors. Ubiquitin recognition receptors are multiple in nature, but they share common areas that serve to recognize and bind to ubiquitin, and areas that allow recruitment of LC3 for the autophagophore. The receptors depicted are Neighbor of BRCA1 Gene 1 (NBR1), Ubiquitin-Binding Protein P62 (p62), nuclear dot protein 52; also known as calcium binding and coiled-coil domain 2 [CALCOCO2] (NDP52), optineurin (OPTN), Tax1-binding protein 1 (Tax1), Toll-Interacting Protein (TOLLIP), and NIX/BNIP3L [BCL2/adenovirus E1B $19 \mathrm{kDa}$ interacting protein 3-like] (NIX/BNIP3). The ubiquitin binding domains are: ubiquitin-associated domain (UBA), Ubiquitin binding in ABIN and NEMO domain (UBAN), Ubiquitin-binding zinc finger domain (UBZ), Endoplasmic reticulum-associated degradation domain (Cue). The LC3 recruiting domains are: LC3-interacting region (LIR), non-canonical LIR motif (CLIR), and LC3 recognition sequence (LRS).

Neighbor of BRCA1 gene 1 (NBR1) is another adaptor protein with remarkable similarity to p62 (Figure 3). However, NBR1 is larger than p62, and its dimerization is mediated by a coiled-coil domain. Through its PB1 domain NBR1 interacts with p62 [62], but can also bind ubiquitin and LC3/GABARAP independently of p62, mediating autophagosomal degradation of ubiquitylated targets. Similar to p62, NBR1 accumulates in inclusion bodies upon autophagy inhibition and is required for the crosslinking of ubiquitylated proteins and aggrephagy [63]. Knockdown and overexpression experiments have shown that NBR1 is a major autophagy receptor for peroxisomes [64].

Optineurin (OPTN) is an adaptor protein with roles in signal transduction, membrane trafficking, and cell division. Optineurin possesses several coiled-coil domains that mediate its oligomerization, a LIR, and C-terminal UBAN and UBZ domains (Figure 3). Optineurin interacts with misfolded proteins in both ubiquitin-dependent and -independent fashion to mediate aggrephagy. TBK1 binds and phosphorylates optineurin within its LIR motif (Ser177), thereby enhancing its interaction with LC3/GABARAPs and potentiating target clearance [65]. Especially, the LIR of optineurin is required for aggrephagy and xenophagy [66], to restrict intracellular pathogens [65]. Increased expression is 
linked to glaucoma and amyotrophic lateral sclerosis (ALS) and is frequently found in pathological protein inclusions (reviewed in [67]).

The Calcium binding and Coiled-Coil Domain 2 (CALCOCO2; best known as NDP52 (nuclear dot protein $52 \mathrm{kDa}$ )) possesses a coiled-coil region, a noncanonical LIR, and a C-terminal UBZ domain [68]. Together with its close homologue Tax1bp1, NDP52 is localized to autophagosomes and subject to autophagic turnover $[69,70]$. NDP52 is recruited by intracellular Salmonella, binds ubiquitylated bacteria, and is an important xenophagy receptor. NDP52 can also be engaged indirectly via the intracellular lectin galectin 8 to interact with glycans and thereby participate in the clearance of protein aggregates [66].

While these receptors all mediate degradation of ubiquitylated cargos, other more specific adaptors act on removal of damaged or surplus organelles They recognize particular binding partners on the surface of their target organelle and, through their LIR sequence, ensure their delivery to the maturing autophagosome [71]. For example, mitophagy critically relies on BCL2 interacting protein 3-like (BNIP3L; best known as NIX) which requires LIR phosphorylation and receptor dimerization for proper BNIP3L-dependent mitophagy initiation and progression [72]. Upon induced expression or activation by hypoxia, these receptors localize to OMM and through their LIR motifs directly induce both formation of autophagosomes and mitophagy [73,74]. FUN14 domain containing 1 (FUNDC1), a protein of the outer mitochondrial membrane, also operates as autophagy receptor in response to hypoxia [73]. It contains three transmembrane domains and a cytosolic N-terminal part harboring a LIR that when phosphorylated at Tyr18 by Src regulates the interaction between FUNDC1 with LC3 [75]. TOLL-interacting protein (Tollip) also recruits and coordinates polyQ aggresome degradation via late endosome pathway in cellular models for Huntington's disease, and it is considered more potent than p62 for polyQ aggresome clearance [76].

\section{Signals That Determine Proteasomal and Lysosomal Degradation}

The UPR regulatory proteins, PERK, IRE1 $\alpha$ and ATF6 $\alpha$ on the ER activate their own downstream pathways toward autophagy. The PERK-eIF2 $\alpha$ sub-pathway facilitates the synthesis of the transcription factors ATF4 and CHOP, upregulating the expression of more than a dozen ATG genes [77] as well as LC3 lipidation and autophagosome biogenesis [78]. Meanwhile, activated IRE1 recruits TRAF2 to induce the phosphorylation of JNK. Phospho-JNK activates the expression of autophagic core genes via the XBP1s transcription factor and phosphorylates Bcl-2, leading to the dissociation of phospho-Bcl-2 from the PI3K class II complex and, thus, autophagosome biogenesis [79]. Finally, ATF6 migrates to and cleaved in the Golgi body and translocates to the nucleus, where it forms a heterodimeric transcription factor with C/EBP- $\beta$ to induce the expression of DAPK1 and its phosphorylation of beclin-1 for autophagosome formation [80].

Cellular proteins containing a motif that are chemically related to the pentapeptide Lys-Phe-Glu-Arg-Gln (KFERQ) are recognized by cytoplasmic heat-shock chaperone HSC70 and its associated co-chaperones. While this chaperone-mediated autophagy (CMA) is ubiquitin-independent, lysosomes also have a ubiquitin-dependent selective system that is important during basal autophagy and starvation-induced autophagy (Figure 4). Histone deacetylase-6 (HDAC6) is a central component of basal autophagy, binds polyubiquitylated misfolded proteins and dynein motors, and by regulating microtubule acetylation loads misfolded proteins onto the microtubules for retrograde transport to the microtubule organizing center (MTOC) or aggresomes [81]. The cargo in turn assembles an F-actin cytoskeleton network that stimulates autophagosome-lysosome fusion [82]. SQSTM1/p62 and casein kinase II (CKII) increase the deacetylase activity by interacting with or phosphorylating HDAC6, respectively. Further, p97 [83], tripartite motif containing 50 (TRIM50), an E3 ubiquitin-ligase, and the cytokine-inducible ubiquitin-like modifier, FAT10/ubiquitin D, UBD, by associating with HDAC6, sequester polyubiquitylated proteins to the aggresome [84]. The distinct nature of basal autophagy is highlighted by the fact that HDAC6 and actin are dispensable for starvation-induced autophagy [82]. 
When the proteasomal function is inhibited and proteotoxic stress increases, Bcl-2-associated athanogene 3 (BAG3), is induced and interacts with HSP70 and with the dynein-dynactin motor complex to sequester proteins into aggresomes [1]. Therefore, Hsp70-Bag3 complex functions as an important signaling node that senses proteotoxicity and triggers protein aggregate formation [85]. Similarly, BAG-1 interacts with Hsc70 and Hsp70 chaperones, and functions as a link to the ubiquitin/proteasome system. Therefore, the BAG proteins, through their ubiquitin-like domain in the $\mathrm{N}$-terminus, are considered sensors for enrichment of misfolded proteins and initiate the transport of aggregates to the lysosome for degradation (Figure 4). After interacting with the LAMP2A, the substrate is internalized through the membrane into the lysosomal lumen with the assistance of luminal HSC70 chaperone and rapidly degraded by luminal-resident proteases [86].

HSPB8 by interacting with BAG3 may define the assembly of primary deposit sites for ubiquitylated cytosolic proteins and facilitate their triaging for repair or degradation. HSPB8 and BAG3 appear to modulate both $\mathrm{p} 62$ phosphorylation and p62 levels, and thereby control the p62 sequestering activity [80]. Therefore, HSPB8 and BAG3 could be early sensors for switching the unfolded protein response proteasome pathway to autophagosome formation and lysosomal degradation.

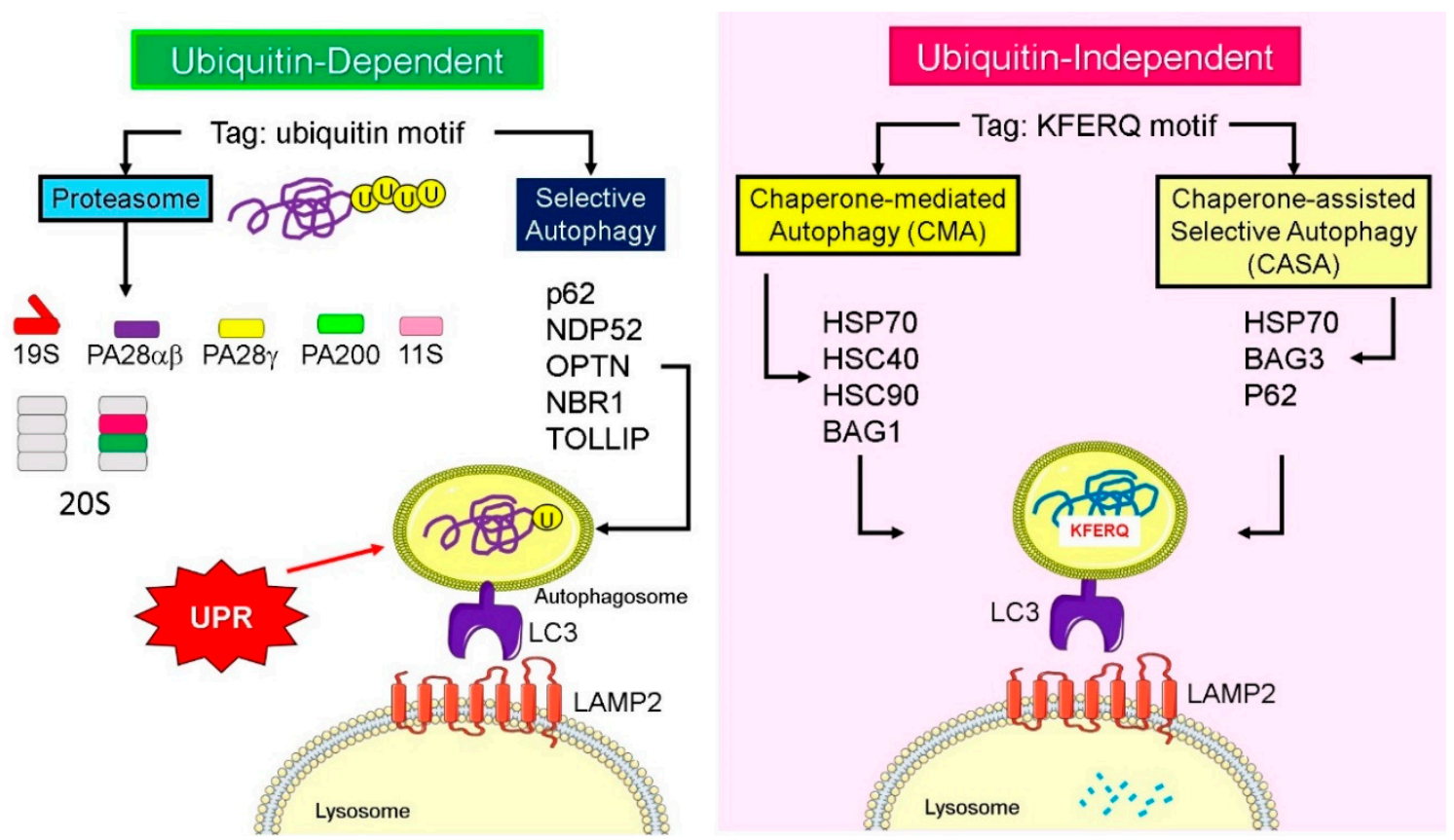

Figure 4. Adaptation for ubiquitin-dependent and -independent protein degradation. Combinations of proteasomal regulatory particles and autophagy adaptor proteins and possible heat-shock proteins and Bcl-2-associated athanogene proteins that allow adaptation of the protein degradation machinery depending on the cellular needs. Ubiquitylated proteins can be recognized various types of regulatory particles or by adaptive proteins that allow lysosomal degradation. Proteins with a specific recognition motif are either recognized by the chaperone-mediated (CMA) or chaperone-assisted selective (CASA) autophagy mechanisms to guide the cargo into the lysosomal degradation.

\section{Concluding Remarks}

The cell has a highly balanced and targeted ubiquitylated system that tags misfolded proteins for elimination before they cause toxic damage to the complex network of processes that help survival. This review summarizes numerous studies that describe how the protein degradation machinery adapts to the needs of the cell. Depending on physiological state of the cell a complex proteasomal machinery that can adapt to cellular conditions by modifying its location and its regulatory units help to selectively attract the tagged proteins. The removed ubiquitin and the amino acids of degraded proteins are then recycled for new protein synthesis and antigen presentation. In addition, the UBL 
proteins together with scaffolding proteins and heat shock centers have evolved mechanisms to recognize larger degradation units, form double membranes that engulf selected aggregates for fusing with lysosomes to degrade and recycle the amino acid components. While both the proteasomal and lysosomal degradation systems work in tandem at baseline, a separate set of proteins signal either the assembly of specialized proteasomes or a set of adaptors activate the lysosomal degradation pathway to adapt to the need of the cell. Therefore, these systems fine-tune the speed of protein degradation depending on the environment, including pollutants that generate ROS or infectious agents that can initiate foreign protein synthesis. While components of the protein degradation system are somewhat understood, the sensors that allow speedy adaptation to support the innate and adaptive immunity of the organism are yet to be uncovered. Continued research effort in this area will help develop more effective treatment strategies for chronic inflammatory diseases and cancer.

Funding: This research was funded by the National Institutes of Health, grant numbers RO1HL068111 and ES015482 (to Y.T.).

Conflicts of Interest: The authors declare no conflict of interest.

\section{References}

1. Dong, Z.; Cui, H. The Autophagy-Lysosomal Pathways and Their Emerging Roles in Modulating Proteostasis in Tumors. Cells 2018, 8, 4. [CrossRef] [PubMed]

2. Clague, M.J.; Urbé, S. Ubiquitin: Same Molecule, Different Degradation Pathways. Cell 2010, 143, $682-685$. [CrossRef] [PubMed]

3. Kim, E.; Park, S.; Lee, J.H.; Mun, J.Y.; Choi, W.H.; Yun, Y.; Lee, J.; Kim, J.H.; Kang, M.-J.; Lee, M.J. Dual Function of USP14 Deubiquitinase in Cellular Proteasomal Activity and Autophagic Flux. Cell Rep. 2018, 24, 732-743. [CrossRef] [PubMed]

4. Gan, J.; Leestemaker, Y.; Sapmaz, A.; Ovaa, H. Highlighting the Proteasome: Using Fluorescence to Visualize Proteasome Activity and Distribution. Front. Mol. Biosci. 2019, 6, 14. [CrossRef]

5. Morozov, A.V.; Karpov, V.L. Proteasomes and Several Aspects of Their Heterogeneity Relevant to Cancer. Front. Oncol. 2019, 9, 761. [CrossRef]

6. Tanaka, K. The proteasome: Overview of structure and functions. Proc. Jpn. Acad. Ser. B 2009, 85, 12-36. [CrossRef]

7. Livneh, I.; Cohen-Kaplan, V.; Cohen-Rosenzweig, C.; Avni, N.; Ciechanover, A. The life cycle of the $26 \mathrm{~S}$ proteasome: From birth, through regulation and function, and onto its death. Cell Res. 2016, 26, 869-885. [CrossRef]

8. Saeki, Y. Ubiquitin recognition by the proteasome. J. Biochem. 2017, 161, 113-124. [CrossRef]

9. Hoeller, D.; Dikic, I. How the proteasome is degraded. Proc. Natl. Acad. Sci. USA 2016, 113, 13266-13268. [CrossRef]

10. Koulich, E.; Li, X.; DeMartino, G.N. Relative Structural and Functional Roles of Multiple Deubiquitylating Proteins Associated with Mammalian 26S Proteasome. Mol. Boil. Cell 2008, 19, 1072-1082. [CrossRef]

11. Finley, D. Recognition and processing of ubiquitin-protein conjugates by the proteasome. Annu. Rev. Biochem. 2009, 78, 477-513. [CrossRef] [PubMed]

12. Krzywda, S.; Brzozowski, A.M.; Higashitsuji, H.; Fujita, J.; Welchman, R.; Dawson, S.; Mayer, R.J.; Wilkinson, A.J. The Crystal Structure of Gankyrin, an Oncoprotein Found in Complexes with Cyclin-dependent Kinase 4, a 19 S Proteasomal ATPase Regulator, and the Tumor Suppressors Rb and p53. J. Boil. Chem. 2003, 279, 1541-1545. [CrossRef] [PubMed]

13. Kaneko, T.; Hamazaki, J.; Iemura, S.-I.; Sasaki, K.; Furuyama, K.; Natsume, T.; Tanaka, K.; Murata, S. Assembly Pathway of the Mammalian Proteasome Base Subcomplex Is Mediated by Multiple Specific Chaperones. Cell 2009, 137, 914-925. [CrossRef] [PubMed]

14. Lu, Y.; Wu, J.; Dong, Y.; Chen, S.; Sun, S.; Ma, Y.-B.; Ouyang, Q.; Finley, D.; Kirschner, M.W.; Mao, Y.J. Conformational Landscape of the p28-Bound Human Proteasome Regulatory Particle. Mol. Cell 2017, 67, 322-333.e6. [CrossRef] [PubMed] 
15. Livnat-Levanon, N.; Kevei, E.; Kleifeld, O.; Krutauz, D.; Segref, A.; Rinaldi, T.; Erpapazoglou, Z.; Cohen, M.M.; Reis, N.; Hoppe, T.; et al. Reversible 26S Proteasome Disassembly upon Mitochondrial Stress. Cell Rep. 2014, 7, 1371-1380. [CrossRef] [PubMed]

16. Wang, X.; Chemmama, I.E.; Yu, C.; Huszagh, A.; Xu, Y.; Viner, R.; Block, S.A.; Cimermancic, P.; Rychnovsky, S.D.; Ye, Y.; et al. The proteasome-interacting Ecm 29 protein disassembles the 26S proteasome in response to oxidative stress. J. Boil. Chem. 2017, 292, 16310-16320. [CrossRef]

17. Pickering, A.M.; Davies, K.J. Differential roles of proteasome and immunoproteasome regulators Pa28alphabeta, Pa28gamma and Pa200 in the degradation of oxidized proteins. Arch. Biochem. Biophys. 2012, 523, 181-190. [CrossRef] [PubMed]

18. Yewdell, J.W. Immunoproteasomes: Regulating the regulator. Proc. Natl. Acad. Sci. USA 2005, 102, 9089-9090. [CrossRef]

19. Ferrington, D.A.; Gregerson, D.S. Immunoproteasomes: Structure, function, and antigen presentation. Prog. Mol. Biol. Transl. Sci. 2012, 109, 75-112.

20. Murata, S.; Takahama, Y.; Tanaka, K. Thymoproteasome: Probable role in generating positively selecting peptides. Curr. Opin. Immunol. 2008, 20, 192-196. [CrossRef]

21. Wendler, P.; Enenkel, C. Nuclear Transport of Yeast Proteasomes. Front. Mol. Biosci. 2019, 6, 34. [CrossRef] [PubMed]

22. Palmer, A.; Mason, G.G.; Paramio, J.M.; Knecht, E.; Rivett, A.J. Changes in proteasome localization during the cell cycle. Eur. J. Cell Boil. 1994, 64, 163-175.

23. Albert, S.; Schaffer, M.; Beck, F.; Mosalaganti, S.; Asano, S.; Thomas, H.F.; Plitzko, J.M.; Beck, M.; Baumeister, W.; Engel, B.D. Proteasomes tether to two distinct sites at the nuclear pore complex. Proc. Natl. Acad. Sci. USA 2017, 114, 13726-13731. [CrossRef] [PubMed]

24. Koch, B.; Yu, H.-G. Regulation of inner nuclear membrane associated protein degradation. Nucleus 2019, 10, 169-180. [CrossRef] [PubMed]

25. Niepel, M.; Molloy, K.R.; Williams, R.; Farr, J.C.; Meinema, A.C.; Vecchietti, N.; Cristea, I.M.; Chait, B.T.; Rout, M.P.; Strambio-De-Castillia, C. The nuclear basket proteins Mlp1p and Mlp2p are part of a dynamic interactome including Esc1p and the proteasome. Mol. Boil. Cell 2013, 24, 3920-3938. [CrossRef]

26. Husnjak, K.; Dikic, I. Ubiquitin-Binding Proteins: Decoders of Ubiquitin-Mediated Cellular Functions. Annu. Rev. Biochem. 2012, 81, 291-322. [CrossRef]

27. Marblestone, J.G.; Butt, S.; McKelvey, D.M.; Sterner, D.E.; Mattern, M.R.; Nicholson, B.; Eddins, M.J. Comprehensive Ubiquitin E2 Profiling of Ten Ubiquitin E3 Ligases. Cell Biophys. 2013, 67, $161-167$. [CrossRef]

28. Collins, G.A.; Goldberg, A.L. The Logic of the 26S Proteasome. Cell 2017, 169, 792-806. [CrossRef]

29. Shoji, S.; Hanada, K.; Ohsawa, N.; Shirouzu, M. Central catalytic domain of BRAP (RNF52) recognizes the types of ubiquitin chains and utilizes oligo-ubiquitin for ubiquitylation. Biochem. J. 2017, 474, 3207-3226. [CrossRef]

30. Hurley, J.H.; Lee, S.; Prag, G. Ubiquitin-binding domains. Biochem. J. 2006, 399, 361-372. [CrossRef]

31. Grice, G.L.; Nathan, J.A. The recognition of ubiquitinated proteins by the proteasome. Cell. Mol. Life Sci. 2016, 73, 3497-3506. [CrossRef] [PubMed]

32. Asher, G.; Lotem, J.; Sachs, L.; Kahana, C.; Shaul, Y. Mdm-2 and ubiquitin-independent p53 proteasomal degradation regulated by NQO1. Proc. Natl. Acad. Sci. USA 2002, 99, 13125-13130. [CrossRef] [PubMed]

33. Wiggins, C.M.; Tsvetkov, P.; Johnson, M.; Joyce, C.L.; Lamb, C.A.; Bryant, N.J.; Komander, D.; Shaul, Y.; Cook, S.J. BIM(EL), an intrinsically disordered protein, is degraded by 205 proteasomes in the absence of poly-ubiquitylation. J. Cell Sci. 2011, 124, 969-977. [CrossRef] [PubMed]

34. Craxton, A.; Butterworth, M.; Harper, N.; Fairall, L.; Schwabe, J.; Ciechanover, A.; Cohen, G.M. NOXA, a sensor of proteasome integrity, is degraded by $26 \mathrm{~S}$ proteasomes by an ubiquitin-independent pathway that is blocked by MCL-1. Cell Death Differ. 2012, 19, 1424-1434. [CrossRef]

35. Prakash, S.; Tian, L.; Ratliff, K.S.; E Lehotzky, R.; Matouschek, A. An unstructured initiation site is required for efficient proteasome-mediated degradation. Nat. Struct. Mol. Boil. 2004, 11, 830-837. [CrossRef]

36. Krappmann, D.; Wulczyn, F.G.; Scheidereit, C. Different mechanisms control signal-induced degradation and basal turnover of the NF-kappaB inhibitor IkappaB alpha in vivo. EMBO J. 1996, 15, 6716-6726. [CrossRef]

37. Saftig, P.; Klumperman, J. Lysosome biogenesis and lysosomal membrane proteins: Trafficking meets function. Nat. Rev. Mol. Cell Boil. 2009, 10, 623-635. [CrossRef] 
38. Braulke, T.; Bonifacino, J.S. Sorting of lysosomal proteins. Biochim. Biophys. Acta (BBA)-Bioenerg. 2009, 1793, 605-614. [CrossRef]

39. Bonam, S.R.; Wang, F.; Muller, S. Lysosomes as a therapeutic target. Nat. Rev. Drug Discov. 2019, 18, 923-948. [CrossRef]

40. Griffiths, G.; Hoflack, B.; Simons, K.; Mellman, I.; Kornfeld, S. The mannose 6-phosphate receptor and the biogenesis of lysosomes. Cell 1988, 52, 329-341. [CrossRef]

41. Jongsma, M.L.; Berlin, I.; Wijdeven, R.H.; Janssen, L.; Janssen, G.M.; Garstka, M.A.; Janssen, H.; Mensink, M.; Van Veelen, P.; Spaapen, R.M.; et al. An ER-Associated Pathway Defines Endosomal Architecture for Controlled Cargo Transport. Cell 2016, 166, 152-166. [CrossRef] [PubMed]

42. Ballabio, A.; Bonifacino, J.S. Lysosomes as dynamic regulators of cell and organismal homeostasis. Nat. Rev. Mol. Cell Boil. 2019, 21, 101-118. [CrossRef] [PubMed]

43. Bonifacino, J.S.; Neefjes, J. Moving and positioning the endolysosomal system. Curr. Opin. Cell Boil. 2017, 47, 1-8. [CrossRef] [PubMed]

44. Dubnikov, T.; Ben-Gedalya, T.; Cohen, E. Protein Quality Control in Health and Disease. Cold Spring Harb. Perspect. Boil. 2016, 9, a023523. [CrossRef] [PubMed]

45. Lecker, S.H.; Goldberg, A.L.; Mitch, W.E. Protein Degradation by the Ubiquitin-Proteasome Pathway in Normal and Disease States. J. Am. Soc. Nephrol. 2006, 17, 1807-1819. [CrossRef] [PubMed]

46. Qin, H.; Shao, Q.; Igdoura, S.A.; Alaoui-Jamali, M.A.; Laird, D. Lysosomal and Proteasomal Degradation Play Distinct Roles in the Life Cycle of Cx43 in Gap Junctional Intercellular Communication-deficient and -competent Breast Tumor Cells. J. Boil. Chem. 2003, 278, 30005-30014. [CrossRef]

47. Mizushima, N.; Yoshimori, T.; Ohsumi, Y. The Role of Atg Proteins in Autophagosome Formation. Annu. Rev. Cell Dev. Boil. 2011, 27, 107-132. [CrossRef]

48. Galluzzi, L.; Baehrecke, E.H.; Ballabio, A.; Boya, P.; Pedro, J.M.B.-S.; Cecconi, F.; Choi, A.M.; Chu, C.T.; Codogno, P.; Colombo, M.I.; et al. Molecular definitions of autophagy and related processes. EMBO J. 2017, 36, 1811-1836. [CrossRef]

49. Stolz, A.; Ernst, A.; Dikic, I. Cargo recognition and trafficking in selective autophagy. Nat. Cell Biol. 2014, 16, 495-501. [CrossRef]

50. Krick, R.; Bremer, S.; Welter, E.; Schlotterhose, P.; Muehe, Y.; Eskelinen, E.L.; Thumm, M. Cdc48/p97 and Shp1/p47 regulate autophagosome biogenesis in concert with ubiquitin-like Atg8. J. Cell Biol. 2010, 190, 965-973. [CrossRef]

51. Hara, T.; Nakamura, K.; Matsui, M.; Yamamoto, A.; Nakahara, Y.; Suzuki-Migishima, R.; Yokoyama, M.; Mishima, K.; Saito, I.; Okano, H.; et al. Suppression of basal autophagy in neural cells causes neurodegenerative disease in mice. Nature 2006, 441, 885-889. [CrossRef] [PubMed]

52. Juhasz, G.; Érdi, B.; Sass, M.; Neufeld, T.P. Atg7-dependent autophagy promotes neuronal health, stress tolerance, and longevity but is dispensable for metamorphosis in Drosophila. Genes Dev. 2007, 21, 3061-3066. [CrossRef] [PubMed]

53. Bjørkøy, G.; Lamark, T.; Brech, A.; Outzen, H.; Perander, M.; Øvervatn, A.; Stenmark, H.; Johansen, T. p62/SQSTM1 forms protein aggregates degraded by autophagy and has a protective effect on huntingtin-induced cell death. J. Cell Biol. 2005, 171, 603-614. [CrossRef] [PubMed]

54. Pankiv, S.; Clausen, T.H.; Lamark, T.; Brech, A.; Bruun, J.A.; Outzen, H.; Øvervatn, A.; Bjørkøy, G.; Johansen, T. p62/SQSTM1 binds directly to Atg8/LC3 to facilitate degradation of ubiquitinated protein aggregates by autophagy. J. Biol. Chem. 2007, 282, 24131-24145. [CrossRef] [PubMed]

55. Moscat, J.; Diaz-Meco, M.T.; Wooten, M.W. Signal integration and diversification through the p62 scaffold protein. Trends Biochem. Sci. 2007, 32, 95-100. [CrossRef]

56. Sumimoto, H.; Kamakura, S.; Ito, T. Structure and Function of the PB1 Domain, a Protein Interaction Module Conserved in Animals, Fungi, Amoebas, and Plants. Sci. STKE 2007, 2007, re6. [CrossRef]

57. Johansen, T.; Lamark, T. Selective autophagy mediated by autophagic adapter proteins. Autophagy 2011, 7 , 279-296. [CrossRef]

58. Komatsu, M.; Kurokawa, H.; Waguri, S.; Taguchi, K.; Kobayashi, A.; Ichimura, Y.; Sou, Y.-S.; Ueno, I.; Sakamoto, A.; Tong, K.I.; et al. The selective autophagy substrate p62 activates the stress responsive transcription factor Nrf2 through inactivation of Keap1. Nature 2010, 12, 213-223. [CrossRef]

59. Rogov, V.; Dötsch, V.; Johansen, T.; Kirkin, V. Interactions between Autophagy Receptors and Ubiquitin-like Proteins Form the Molecular Basis for Selective Autophagy. Mol. Cell 2014, 53, 167-178. [CrossRef] 
60. Fujita, N.; Morita, E.; Itoh, T.; Tanaka, A.; Nakaoka, M.; Osada, Y.; Umemoto, T.; Saitoh, T.; Nakatogawa, H.; Kobayashi, S.; et al. Recruitment of the autophagic machinery to endosomes during infection is mediated by ubiquitin. J. Cell Boil. 2013, 203, 115-128. [CrossRef]

61. Alemu, E.A.; Lamark, T.; Torgersen, K.M.; Birgisdottir, Å.B.; Larsen, K.B.; Jain, A.; Olsvik, H.; Øvervatn, A.; Kirkin, V.; Johansen, T. ATG8 Family Proteins Act as Scaffolds for Assembly of the ULK Complex. J. Boil. Chem. 2012, 287, 39275-39290. [CrossRef] [PubMed]

62. Lamark, T.; Perander, M.; Outzen, H.; Kristiansen, K.; Øvervatn, A.; Michaelsen, E.; Bjørkøy, G.; Johansen, T. Interaction Codes within the Family of Mammalian Phox and Bem1p Domain-containing Proteins. J. Boil. Chem. 2003, 278, 34568-34581. [CrossRef] [PubMed]

63. Kirkin, V.; Lamark, T.; Sou, Y.-S.; Bjørkøy, G.; Nunn, J.L.; Bruun, J.A.; Shvets, E.; McEwan, D.G.; Clausen, T.H.; Wild, P.; et al. A Role for NBR1 in Autophagosomal Degradation of Ubiquitinated Substrates. Mol. Cell 2009, 33, 505-516. [CrossRef]

64. Deosaran, E.; Larsen, K.B.; Hua, R.; Sargent, G.; Wang, Y.; Kim, S.; Lamark, T.; Jauregui, M.; Law, K.; Lippincott-Schwartz, J.; et al. NBR1 acts as an autophagy receptor for peroxisomes. J. Cell Sci. 2012, 126, 939-952. [CrossRef] [PubMed]

65. Wild, P.; Farhan, H.; McEwan, D.G.; Wagner, S.; Rogov, V.V.; Brady, N.R.; Richter, B.; Korac, J.; Waidmann, O.; Choudhary, C.; et al. Phosphorylation of the Autophagy Receptor Optineurin Restricts Salmonella Growth. Science 2011, 333, 228-233. [CrossRef]

66. Korac, J.; Schaeffer, V.; Kovacević, I.; Clement, A.M.; Jungblut, B.; Behl, C.; Terzic, J.; Dikic, I. Ubiquitin-independent function of optineurin in autophagic clearance of protein aggregates. J. Cell Sci. 2012, 126, 580-592. [CrossRef]

67. Kachaner, D.; Génin, P.; Laplantine, E.; Weil, R. Toward an integrative view of Optineurin functions. Cell Cycle 2012, 11, 2808-2818. [CrossRef]

68. Von Muhlinen, N.; Akutsu, M.; Ravenhill, B.J.; Foeglein, Á.; Bloor, S.; Rutherford, T.J.; Freund, S.M.; Komander, D.; Randow, F. LC3C, Bound Selectively by a Noncanonical LIR Motif in NDP52, Is Required for Antibacterial Autophagy. Mol. Cell 2012, 48, 329-342. [CrossRef]

69. Newman, A.C.; Scholefield, C.L.; Kemp, A.J.; Newman, M.; McIver, E.G.; Kamal, A.; Wilkinson, S. TBK1 kinase addiction in lung cancer cells is mediated via autophagy of Tax1bp1/Ndp52 and non-canonical NF-kB signalling. PLoS ONE 2012, 7, e50672. [CrossRef]

70. Thurston, T.L.M.; Ryzhakov, G.; Bloor, S.; Von Muhlinen, N.; Randow, F. The TBK1 adaptor and autophagy receptor NDP52 restricts the proliferation of ubiquitin-coated bacteria. Nat. Immunol. 2009, 10, 1215-1221. [CrossRef]

71. Farré, J.-C.; Burkenroad, A.; Burnett, S.F.; Subramani, S. Phosphorylation of mitophagy and pexophagy receptors coordinates their interaction with Atg8 and Atg11. EMBO Rep. 2013, 14, 441-449. [CrossRef] [PubMed]

72. Schweers, R.L.; Zhang, J.; Randall, M.S.; Loyd, M.R.; Li, W.; Dorsey, F.C.; Kundu, M.; Opferman, J.T.; Cleveland, J.L.; Miller, J.L.; et al. NIX is required for programmed mitochondrial clearance during reticulocyte maturation. Proc. Natl. Acad. Sci. USA 2007, 104, 19500-19505. [CrossRef] [PubMed]

73. Lampert, M.A.; Orogo, A.M.; Najor, R.H.; Hammerling, B.C.; Leon, L.J.; Wang, B.; Kim, T.; Sussman, M.A.; Gustafsson, Å.B. BNIP3L/NIX and FUNDC1-mediated mitophagy is required for mitochondrial network remodeling during cardiac progenitor cell differentiation. Autophagy 2019, 15, 1182-1198. [CrossRef] [PubMed]

74. Novak, I.; Kirkin, V.; McEwan, D.G.; Zhang, J.; Wild, P.; Rozenknop, A.; Rogov, V.; Löhr, F.; Popovic, D.; Occhipinti, A.; et al. Nix is a selective autophagy receptor for mitochondrial clearance. EMBO Rep. 2009, 11, 45-51. [CrossRef]

75. Liu, L.; Feng, D.; Chen, G.; Chen, M.; Zheng, Q.; Song, P.; Ma, Q.; Zhu, C.; Wang, R.; Qi, W.; et al. Mitochondrial outer-membrane protein FUNDC1 mediates hypoxia-induced mitophagy in mammalian cells. Nature 2012, 14, 177-185. [CrossRef]

76. Lu, J.-H.; He, L.; Behrends, C.; Araki, M.; Araki, K.; Wang, Q.J.; Catanzaro, J.M.; Friedman, S.L.; Zong, W.-X.; Fiel, M.I.; et al. NRBF2 regulates autophagy and prevents liver injury by modulating Atg14L-linked phosphatidylinositol-3 kinase III activity. Nat. Commun. 2014, 5, 3920. [CrossRef] 
77. B'chir, W.; Maurin, A.C.; Carraro, V.; Averous, J.; Jousse, C.; Muranishi, Y.; Parry, L.; Stepien, G.; Fafournoux, P.; Bruhat, A. The eIF2alpha/ATF4 pathway is essential for stress-induced autophagy gene expression. Nucleic Acids Res. 2013, 41, 7683-7699. [CrossRef]

78. Bao, Y.; Pu, Y.; Yu, X.; Gregory, B.D.; Srivastava, R.; Howell, S.H.; Bassham, D.C. IRE1B degrades RNAs encoding proteins that interfere with the induction of autophagy by ER stress in Arabidopsis thaliana. Autophagy 2018, 14, 1562-1573. [CrossRef]

79. Deegan, S.; Koryga, I.; Glynn, S.A.; Gupta, S.; Gorman, A.M.; Samali, A. A close connection between the PERK and IRE arms of the UPR and the transcriptional regulation of autophagy. Biochem. Biophys. Res. Commun. 2015, 456, 305-311. [CrossRef]

80. Guilbert, S.M.; Lambert, H.; Rodrigue, M.-A.; Fuchs, M.; Landry, J.; Lavoie, J.N. HSPB8 and BAG3 cooperate to promote spatial sequestration of ubiquitinated proteins and coordinate the cellular adaptive response to proteasome insufficiency. FASEB J. 2018, 32, 3518-3535. [CrossRef]

81. Gao, Y.-S.; Hubbert, C.C.; Lu, J.; Lee, Y.-S.; Lee, J.Y.; Yao, T.-P. Histone Deacetylase 6 Regulates Growth Factor-Induced Actin Remodeling and Endocytosis. Mol. Cell. Boil. 2007, 27, 8637-8647. [CrossRef] [PubMed]

82. Lee, J.Y.; Koga, H.; Kawaguchi, Y.; Tang, W.; Wong, E.; Gao, Y.-S.; Pandey, U.B.; Kaushik, S.; Tresse, E.; Lu, J.; et al. HDAC6 controls autophagosome maturation essential for ubiquitin-selective quality-control autophagy. EMBO J. 2010, 29, 969-980. [CrossRef] [PubMed]

83. Ju, J.S.; Miller, S.E.; Hanson, P.I.; Weihl, C.C. Impaired protein aggregate handling and clearance underlie the pathogenesis of p97/VCP-associated disease. J. Biol. Chem. 2008, 283, 30289-30299. [CrossRef] [PubMed]

84. Kalveram, B.; Schmidtke, G.; Groettrup, M. The ubiquitin-like modifier FAT10 interacts with HDAC6 and localizes to aggresomes under proteasome inhibition. J. Cell Sci. 2008, 121, 4079-4088. [CrossRef] [PubMed]

85. Meriin, A.B.; Narayanan, A.; Meng, L.; Alexandrov, I.; Varelas, X.; Cissé, I.I.; Sherman, M.Y. Hsp70-Bag3 complex is a hub for proteotoxicity-induced signaling that controls protein aggregation. Proc. Natl. Acad. Sci. USA 2018, 115, E7043-E7052. [CrossRef] [PubMed]

86. Schneider, J.L.; Suh, Y.; Cuervo, A.M. Deficient Chaperone-Mediated Autophagy in Liver Leads to Metabolic Dysregulation. Cell Metab. 2014, 20, 417-432. [CrossRef]

(C) 2020 by the authors. Licensee MDPI, Basel, Switzerland. This article is an open access article distributed under the terms and conditions of the Creative Commons Attribution (CC BY) license (http://creativecommons.org/licenses/by/4.0/). 